\title{
Bacterial profile of aggressive periodontitis in Morocco: a cross-sectional study
}

\author{
Hanane Chahboun ${ }^{1 \dagger}$, Maria Minguez Arnau², David Herrera², Mariano Sanz ${ }^{2}$ and Oum Keltoum Ennibi ${ }^{1 *+}$
}

\begin{abstract}
Background: Aggressive periodontitis (AgP) is one of the most severe forms of periodontal diseases. In Morocco, Aggregatibacter actinomycetemcomitans has been strongly associated with AgP, however limited knowledge is available about the implication of other periodontal pathogens in this entity. Therefore, the main aim of this study was to evaluate the composition of the subgingival microbiota in Moroccan patients with AgP.

Methods: Subgingival plaque samples were collected from 50 aggressive, 13 localized and 37 generalized periodontitis patients. Samples from 20 chronic periodontitis (ChP) patients were taken as controls. Samples collected from the four deepest periodontal pockets in each patient were pooled in pre-reduced transport fluid and examined by culture.
\end{abstract}

Results: A. actinomycetemcomitans was significantly more frequent $(p=0.004)$ in generalised AgP compared to ChP, and Porphyromonas gingivalis was less prevalent in localized AgP, when compared with generalized AgP $(p=0.040)$ or ChP $(p=0.016)$. Prevotella intermedia, Fusobacterium nucleatum and Tannerella forsythia were also frequently detected in all groups. Mean proportions of A. actinomycetemcomitans were significantly higher in AgP groups, when compared to ChP, and generalized AgP patients harbored significantly higher proportions of $P$. gingivalis and T. forsythia, when compared to localized AgP or ChP.

Conclusions: A. actinomycetemcomitans, P. gingivalis, T. forsythia, P. intermedia and F. nucleatum were frequently detected in this Moroccan population with AgP. Differences in frequency of detection, counts and proportions of A. actinomycetemcomitans, P. gingivalis and T. forsythia suggests the presence of distinct microbiological profiles for localized AgP, generalized AgP and ChP patients.

Keywords: Periodontal pathogens, Aggressive periodontitis, Chronic periodontitis, Subgingival microbiota, A. actinomycetemcomitans

\section{Background}

Aggressive periodontitis (AgP) is a form of periodontitis characterized by rapid and severe periodontal destruction in otherwise young healthy individuals. The etiology of periodontitis is very complex including the dental biofilm, which triggers the immuno-inflammatory response in a susceptible host. This interaction leads to the destruction of the periodontal tissues [1,2]. Pathogenic bacteria are the primary etiology agents in the pathogenesis of periodontitis. The oral biofilm is very complex and count for over 700 species, however only some

\footnotetext{
* Correspondence: o.ennibi@um5s.net.ma

†Equal contributors

'EREB (Research Group of Oral Ecosystem), Faculty of Medicine Dentistry, Mohammed V University, Rabat, Morocco

Full list of author information is available at the end of the article
}

micro-organisms have been specifically associated with periodontal diseases [3]. The majority of periodontal pathogens are Gram-negative and strict anaerobe, acting in synergy. Among the most important species, Aggregatibacter actinomycetemcomitans has been frequently associated with $\operatorname{AgP}[4,5]$. Other bacteria are known as been associated with progression of periodontal destruction, such as Porphyromonas gingivalis, Tannerella forsythia, Treponema denticola, Fusobacterium nucleatum, Prevotella intermedia, Prevotella nigrescens, Campylobacter rectus, Eikenella corrodens and Parvimonas micra [6]. All these bacterial species produce a wide variety of virulent factors enabling them to colonize subgingival sites, to resist the defense mechanisms of the host and to cause periodontal tissue destruction [7]. 
These micro-organisms do not suffice to advance the disease. Indeed, the host immune response modules the evolution of the disease toward destruction or cure [8]. The role of these bacteria in the pathogenesis of the human periodontitis is based on their high frequency of isolation, the ability to adhere to epithelial cells, the ability to produce numerous virulent factors like the extracellular matrix proteins, protease, collagenase, endotoxin (LPS), bacteriocins, hemotactic inhibitors, leucotoxins, cytotoxins, toxic metabolic substances $\left(\mathrm{H}_{2} \mathrm{~S}\right.$, putricines), immunosuppressive proteins, etc. $[9,10]$.

Whereas A. actinomycetemcomitans is widely associated with localized AgP [7,11], P. gingivalis is regarded as the major causative agent in chronic periodontitis (ChP) [12]. Recently, a very strong association between the presence of the JP2 clone of A. actinomycetemcomitans and AgP was demonstrated among adolescents in Morocco [13]. In addition, a prospective longitudinal study has shown that infection with the JP2 clone is likely to be important in the initiation of the disease [14]. However, other periodontopathic bacteria, such as P. gingivalis are also suspected of participating in AgP [15]. It is admitted that AgP is not a mono-infectious disease, and the bacterial profile of this entity has not been studied in depth in Morocco. Thus, identification of the most prevalent bacteria is necessary to understand the bacterial etiology and could help to understand the treatment failure in some cases.

The aim of this study was to characterize the subgingival microbiota in a Moroccan population with AgP, including the evaluation of the presence and quantification, by means of culturing, of $A$. actinomycetemcomitans, $P$. gingivalis, $F$. nucleatum, $C$. rectus, $P$. intermedia/nigrescens, T. forsythia, E. corrodens, P. micra, Eubacterium spp., and Capnocytophaga spp.

\section{Methods}

\section{Study population}

This cross-sectional study was performed with a convenience sample of consecutive patients seeking treatment at the clinical department of Periodontology at the Faculty of Dentistry of Mohammed V Souissi University, Rabat, Morocco (from January 2011 to December 2012).

All subjects were verbally informed about the investigation, and they were asked to sign informed consent. The study was approved by the Medical Ethical Committee of Mohammed V Souissi University, Rabat, Morocco.

Patients, who met the inclusion criteria and sign the informed consent, were entered into the study. All patients had at least 20 teeth, diagnosed as having AgP or $\mathrm{ChP}$, and were $\leq 35$ years of age. The exclusion criteria were patients medically compromised, or having received periodontal or antibiotic treatment within the preceding 6 months, patients under orthodontic treatment, pregnant women or during lactation, and patients who need antibiotic prophylaxis before screening.

\section{Clinical and radiographic examination}

The following clinical variables were scored at six sites per tooth, and in all teeth except third molars: dichotomous plaque presence, bleeding on probing (BOP), probing pocket depth (PPD, assessed to the nearest millimeter using a standard periodontal probe), clinical attachment level (CAL, calculated as the distance from the cemento-enamel junction to the bottom of the periodontal pocket).

A full mouth periapical radiographic examination was also performed to confirm by evidence interproximale bone loss. Bone loss was estimated by determining the ratio of the distance from the cemento-enamel junction to the alveolar bone crest. All clinical data was collected by the same examiner.

The diagnosis for the periodontal status was established for all subjects based on the 1999 International Classification of periodontal diseases and conditions [16]. The used clinical criteria were as follows. For aggressive periodontitis: 1) rapid attachment loss and bone breakdown were evident including at least one incisor and one first molar, 2) pocket depth $\geq 4 \mathrm{~mm}$, clinical attachment loss $\geq 3 \mathrm{~mm}$, presence of bleeding on probing. For chronic periodontitis: extensive deposits of plaque and calculus, more than $10 \%$ of teeth with pocket depth $\geq 4 \mathrm{~mm}$, and at least one site having attachment loss $\geq 3 \mathrm{~mm}$.

\section{Bacterial sampling and analysis}

Sampling collection was done within week after interviewing and clinical examination, by means of pooled subgingival samples from each patient. Subgingival plaque samples were collected from four deep sites, one per quadrant, from each patient.

Supragingival plaque, located in direct proximity to sample sites, was carefully removed using a scaler and cotton gauze. A sterile, absorbent paper point was gently inserted into the apical extent of the periodontal pocket (sulcus). After 20 seconds, the papers were pooled in a tube containing $1.5 \mathrm{ml}$ of reduced transport fluid (RTF) medium [17]. All plaque samples were collected by the same examiner.

\section{Microbiological procedures}

Samples were transferred to the laboratory of Microbiology and Molecular Biology, Faculty of Dentistry, University of Complutense Madrid, Spain, within 24 hours, where they were homogenized by vortexing for $30 \mathrm{~s}$ [18], and serially diluted in phosphate-buffered saline (PBS). At the laboratory, aliquots of $0.1 \mathrm{ml}$ were plated manually for the detection of $A$. actinomycetemcomitans on a specific medium 
[19]. These plates were incubated for 3 days in air with $5 \% \mathrm{CO}_{2}$ at $37^{\circ} \mathrm{C}$. Suspected isolates were identified on the basis of colony morphology (small colony, $1 \mathrm{~mm}$ in diameter, with a dark border and a "star" or "crossed cigars" shaped inner structure) and positive catalase reaction. Sample dilutions were also plated onto a non-selective blood agar plate (Blood Agar Base $\mathrm{II}^{\circ}$, Oxoid, Basingstoke, UK), supplemented with haemine $(5 \mathrm{mg} / \mathrm{l})$, menadione $(1 \mathrm{mg} / \mathrm{l})$ and $5 \%$ sterile horse blood. After 7-14 days of anaerobic incubation $\left(80 \% \mathrm{~N}_{2}, 10 \%\right.$ $\mathrm{CO}_{2}$ and $10 \% \mathrm{H}_{2}$ ), total counts and counts of representative colonies (those with colony morphologies compatible with target pathogen morphology) were performed in the most suitable plates, those harboring between 30 and 300 colonies. Suspected colonies were further identified by microscopy, studying gram staining and enzyme activity (including $\mathrm{N}$-acetyl- $\beta$ - $\mathrm{D}$ glucosaminidase, $\alpha$-glucosidase, $\alpha$-galactosidase, $\alpha$ fucosidase, esculin, indole and trypsin-like activity). In addition, the black pigmented colonies of $P$. gingivalis and $P$. intermedia have been tested under red fluorescent light UV $(360 \mathrm{~nm})$ : negative for $P$. gingivalis and positive for $P$. intermedia [20]. Counts were transformed in colony-forming units per milliliter of the original sample. Total anaerobic counts were calculated, as well as counts of the detected periodontal pathogens (A. actinomycetemcomitans, T. forsythia, P. gingivalis, $P$. intermedia/nigrescens, $P$. micra, C. rectus, E. corrodens. Eubacterium spp., Capnocytophaga spp., and $F$. nucleatum). In addition to the quantitative microbiological data, the frequency of detection and proportions for each bacterial species were also calculated.

\section{Data analysis}

Different groups were compared: AgP and ChP, on one side; and localized and generalized AgP on the other side. The patient was used as experimental unit for observation. Demographic and clinical data were calculated for each subject (mean \pm standard deviation, when needed the median was use). Differences in demographic and clinical parameters among groups were established with the one-way analysis of variance test. Chi square test and Fisher's exact test were employed to compare the frequency of detection of different pathogens between groups. For counts of bacterial species, colony forming units were log transformed to achieve a normal distribution and ANOVA was used as a primary test to compare the three groups; as post hoc test, multiple rank tests were conducted when differences were detected. For proportions of anaerobic microflora, the Kruskal Wallis test was used primarily, while differences were explored post hoc by Mann-Whitney test. $P$ values $<0.05$ were considered statistically significant.

\section{Results}

A total of 70 subjects were recruited in this study, divided in 50 cases of AgP (13 localized, 37 generalized) and 20 of ChP.

\section{Clinical findings}

In the comparison between AgP and ChP, demographic and clinical data of patients are summarized in Table 1. The mean age of patients was significantly lower in AgP than in ChP group $(\mathrm{p}<0.001)$. Pockets were significantly deeper in AgP than in ChP patients $(\mathrm{p}<0.001)$, and CAL was significantly higher for AgP $(\mathrm{p}<0.001)$.

In the comparison between localized and generalized AgP, significantly more sites with plaque and gingival inflammation were observed in generalized $\operatorname{AgP}(\mathrm{p}<0.05)$ (Table 1).

Table 1 Demographic and clinical data in aggressive (localized and generalized) and chronic periodontitis groups

\begin{tabular}{|c|c|c|c|c|}
\hline & $\begin{array}{l}\text { Localized aggressive } \\
\text { periodontitis } \\
\text { (LAgP) } \\
\mathrm{n}=13\end{array}$ & $\begin{array}{l}\text { Generalized aggressive } \\
\text { periodontitis } \\
\text { (GAgP) } \\
\mathrm{n}=37\end{array}$ & $\begin{array}{l}\text { Chronic } \\
\text { periodontitis } \\
(\mathrm{ChP}) \\
\mathrm{n}=20\end{array}$ & $P^{*}$ \\
\hline Gender: female/male ( $\%$ female) & $11 / 2(84.6 \%)$ & $29 / 8(78.4 \%)$ & $16 / 4(80.0 \%)$ & $>0.05$ \\
\hline Age: mean \pm standard deviation (range) & $19.85 \pm 4.616(13 ; 26)$ & $24.43 \pm 5.058(17 ; 36)$ & $28.55 \pm 4.347(21 ; 35)$ & $<0.001$ \\
\hline Plaque index: median (range) & $36.6 \%(25.9-72.5)$ & $80.4 \%(53.9-100.0)$ & $56.2 \%(45.1-76.0)$ & 0.001 \\
\hline Bleeding on probing: median (range) & $30.2 \%(23.1-68.9)$ & $76.8 \%(59.1-100.0)$ & $46.4 \%(33.7-59.9)$ & 0.000 \\
\hline Probing pocket depth: mean \pm standard deviation & $6.23 \pm 1.25$ & $6.05 \pm 0.95$ & $4.46 \pm 0.59$ & $<0.001$ \\
\hline Clinical attachment level: mean \pm standard deviation & $6.03 \pm 1.94$ & $5.18 \pm 1.39$ & $3.09 \pm 1.20$ & $<0.001$ \\
\hline
\end{tabular}

*P value for multiple comparisons by means on ANOVA. Statistically significant differences corresponded to.

Age: LAgP vs GAgP, $\mathrm{p}=0.006 ;$ LAgP vs ChP, $\mathrm{p}<0.001 ; \mathrm{GAgP}$ vs ChP, $\mathrm{p}=0.003$.

Plaque index: LAgP vs GAgP, $\mathrm{p}=0.001 ; \mathrm{GAgP}$ vs $\mathrm{ChP}, \mathrm{p}=0.008$.

Bleeding on probing: LAgP vs GAgP, $\mathrm{p}<0.001 ; \mathrm{GAgP}$ vs ChP, $\mathrm{p}<0.001$.

Probing pocket depth: GAgP vs ChP, $p<0.001$; LAgP vs ChP, $p<0.001$.

Clinical attachment level: GAgP vs ChP, $\mathrm{p}<0.001$; LAgP vs ChP, $\mathrm{p}<0.001$. 
Table 2 Frequencies of detection [n positive (percentage)] of studied bacteria in aggressive periodontitis compared to chronic periodontitis

\begin{tabular}{|c|c|c|c|c|}
\hline & \multicolumn{3}{|c|}{ Aggressive periodontitis } & \multirow{2}{*}{$\begin{array}{l}\text { Chronic } \\
\text { periodontitis }\end{array}$} \\
\hline & $\begin{array}{l}\text { Localized aggressive } \\
\text { periodontitis }\end{array}$ & $\begin{array}{l}\text { Generalized aggressive } \\
\text { periodontitis }\end{array}$ & $\begin{array}{l}\text { All aggressive } \\
\text { periodontitis }\end{array}$ & \\
\hline & $n=13$ & $\mathrm{n}=37$ & $\mathrm{n}=50$ & $\mathrm{n}=\mathbf{2 0}$ \\
\hline A.actinomycetemcomitans* & $6(46.2 \%)$ & $24(64.9 \%)$ & $30(60.0 \%)$ & $5(25.0 \%)$ \\
\hline P. gingivalis* & $8(61.5 \%)$ & $33(89.2 \%)$ & $41(82.0 \%)$ & $12(60.0 \%)$ \\
\hline P. intermedia/nigrescens & $11(84.6 \%)$ & $32(86.5 \%)$ & $43(86.0 \%)$ & $18(90.0 \%)$ \\
\hline T. forsythia & $6(46.2 \%)$ & $24(64.9 \%)$ & $30(60.0 \%)$ & $11(45.0 \%)$ \\
\hline P. micra & $1(7.7 \%)$ & $11(29.7 \%)$ & $12(24.0 \%)$ & $4(20.0 \%)$ \\
\hline C. rectus & $2(15.4 \%)$ & $5(13.5 \%)$ & $7(15.0 \%)$ & $3(15.0 \%)$ \\
\hline F. nucleatum & $10(76.9 \%)$ & $31(82.4 \%)$ & $41(82.0 \%)$ & $16(80.0 \%)$ \\
\hline Capnocytophaga spp. & $4(30.8 \%)$ & $10(27.0 \%)$ & $14(28.0 \%)$ & 7 (35.0\%) \\
\hline E. corrodens & $6(46.2 \%)$ & $9(24.3 \%)$ & 15(30.0\%) & $3(15.0 \%)$ \\
\hline
\end{tabular}

*Statistically significant differences were detected, by means of Chi-square or Fisher Exact test, for.

A.actinomycetemcomitans: AgP vs $\mathrm{ChP}, \mathrm{p}=0.080$; $\mathrm{GAgP}$ vs $\mathrm{ChP}, \mathrm{p}=0.004$.

$P$. gingivalis: $G A g P$ vs $C h P, p=0.016 ; G A g P$ vs $L A g P, p=0.040$.

\section{Microbiological findings}

Frequency of detection

In the comparison between AgP and ChP, a tendency towards statistically significant differences was detected regarding the presence of $A$. actinomycetemcomitans: $60.0 \%$ in $\mathrm{AgP}$ versus $25.0 \%$ in $\mathrm{ChP}(\mathrm{p}=0.08)$. In both groups, $P$. gingivalis, $P$. intermedia, $F$. nucleatum and $T$. forsythia were frequently detected, with no statistically significant differences; however, $P$. gingivalis was more frequent in AgP than in ChP (82,0\% versus 60,0\%, respectively). Capnocytophaga spp., P. micra, and C. rectus showed lower frequencies in both groups. A. actinomycetemcomitans was significantly more frequent in generalized AgP than in ChP $(\mathrm{p}=0.004)$. Also P. gingivalis was more prevalent in GAgP when compared with both LAgP $(\mathrm{p}=0.040)$ and ChP $(\mathrm{p}=0.016)$ Table 2.

\section{Proportions of anaerobic microflora}

Differences in mean proportions of A. actinomycetemcomitans were statistically significant among groups $(\mathrm{p}=0.004)$, corresponding to lower proportions in ChP when compared to localized AgP (tendency, $\mathrm{p}=0.062$ ) and generalized AgP $(\mathrm{p}=0.001)$. For $P$. gingivalis, means proportions were also significantly different among groups $(\mathrm{p}=0.038)$, when higher values for generalized AgP when compared to localized AgP (tendency, $\mathrm{p}=0.064$ ) and

Table 3 Proportions (expressed as mean and standard deviation -sd) of total anaerobic microflora, isolated by culture in localized, generalized aggressive and chronic periodontitis

\begin{tabular}{|c|c|c|c|c|c|c|c|}
\hline & \multirow{2}{*}{\multicolumn{2}{|c|}{$\begin{array}{l}\text { Localized aggressive periodontitis } \\
\text { (LAgP) } n=13\end{array}$}} & \multirow{2}{*}{\multicolumn{2}{|c|}{$\begin{array}{l}\text { Generalized aggressive periodontitis } \\
\text { (GAgP) } n=37\end{array}$}} & \multirow{2}{*}{\multicolumn{2}{|c|}{$\begin{array}{l}\text { Chronic periodontitis } \\
\text { (ChP) } n=20\end{array}$}} & \multirow{3}{*}{$\begin{array}{l}\text { K-W* } \\
\text { p value }\end{array}$} \\
\hline & & & & & & & \\
\hline & mean & sd & mean & sd & mean & sd & \\
\hline A. actinomycetemcomitans & $18.16 \%$ & $29.10 \%$ & $11.55 \%$ & $38.81 \%$ & $0.05 \%$ & $0.18 \%$ & 0.004 \\
\hline P. gingivalis & $12.49 \%$ & $15.21 \%$ & $28.25 \%$ & $27.04 \%$ & $13.78 \%$ & $18.39 \%$ & 0.038 \\
\hline P. intermedia/nigrescens & $5.78 \%$ & $7.07 \%$ & $4.92 \%$ & $7.20 \%$ & $4.78 \%$ & $7.97 \%$ & 0.598 \\
\hline T. forsythia & $1.32 \%$ & $2.58 \%$ & $5.52 \%$ & $8.32 \%$ & $3.03 \%$ & $7.76 \%$ & 0.028 \\
\hline P. micra & $0.09 \%$ & $0.34 \%$ & $0.91 \%$ & $2.40 \%$ & $1.18 \%$ & $2.96 \%$ & 0.298 \\
\hline C. rectus & $0.55 \%$ & $1.79 \%$ & $0.08 \%$ & $0.26 \%$ & $0.10 \%$ & $0.34 \%$ & 0.958 \\
\hline F. nucleatum & $1.96 \%$ & $3.52 \%$ & $1.43 \%$ & $2.11 \%$ & $1.90 \%$ & $1.59 \%$ & 0.266 \\
\hline Capnocytophaga spp. & $0.67 \%$ & $1.59 \%$ & 0.93\% & $3.08 \%$ & $0.12 \%$ & $0.25 \%$ & 0.902 \\
\hline E. corrodens & $0.44 \%$ & $0.87 \%$ & $0.28 \%$ & $1.00 \%$ & $0.18 \%$ & $0.40 \%$ & 0.457 \\
\hline
\end{tabular}

*Kruskal-Wallis test was used to compare the three groups; detected differences were explored by means of Mann Whitney test to compare two groups. Differences corresponded to.

A.actinomycetemcomitans: LAgP vs ChP, $\mathrm{p}=0.062 ; \mathrm{GAgP}$ vs $\mathrm{ChP}, \mathrm{p}=0.001$.

$P$. gingivalis: $\mathrm{LAgP}$ vs GAgP, $\mathrm{p}=0.064 ; \mathrm{GAgP}$ vs $\mathrm{ChP}, \mathrm{p}=0.014$.

T. forsythia: LAgP vs GAgP, $\mathrm{p}=0.027 ; \mathrm{GAgP}$ vs $\mathrm{ChP}, \mathrm{p}=0.045$. 
Table 4 Total anaerobic counts and counts of selected bacterial species (in logarithm, expressed as mean and standard deviation -sd) in localized, generalized and chronic periodontitis

\begin{tabular}{|c|c|c|c|c|c|c|c|}
\hline & \multirow{2}{*}{\multicolumn{2}{|c|}{$\begin{array}{l}\text { Localized aggressive periodontitis } \\
\text { (LAgP) } n=13\end{array}$}} & \multirow{2}{*}{\multicolumn{2}{|c|}{$\begin{array}{l}\text { Generalized aggressive periodontitis } \\
\text { (GAgP) } n=37\end{array}$}} & \multirow{2}{*}{\multicolumn{2}{|c|}{$\begin{array}{l}\text { Chronic periodontitis } \\
\text { (ChP) } n=20\end{array}$}} & \multirow{3}{*}{$\begin{array}{l}\text { ANOVA* } \\
\text { P value }\end{array}$} \\
\hline & & & & & & & \\
\hline & mean & sd & mean & sd & mean & sd & \\
\hline Total counts & 8.41 & 0.69 & 8.90 & 0.62 & 8.47 & 0.52 & 0.011 \\
\hline A. actinomycetemcomitans & 2.62 & 2.99 & 3.32 & 2.62 & 0.81 & 1.47 & 0.019 \\
\hline P. gingivalis & 3.93 & 2.81 & 5.37 & 2.35 & 3.52 & 3.01 & 0.030 \\
\hline P. intermedia/nigrescens & 4.35 & 2.14 & 4.79 & 1.85 & 3.95 & 1.99 & 0.297 \\
\hline T. forsythia & 2.11 & 2.79 & 3.81 & 2.88 & 2.44 & 2.61 & 0.084 \\
\hline P. micra & 0.39 & 1.42 & 1.47 & 2.33 & 1.03 & 2.13 & 0.290 \\
\hline C. rectus & 0.79 & 1.94 & 0.61 & 1.58 & 0.69 & 1.69 & 0.939 \\
\hline F. nucleatum & 3.15 & 2.23 & 4.05 & 1.88 & 3.98 & 1.82 & 0.337 \\
\hline Capnocytophaga spp. & 1.28 & 2.03 & 1.41 & 2.22 & 1.23 & 1.95 & 0.953 \\
\hline E. corrodens & 1.60 & 2.16 & 1.09 & 2.19 & 0.94 & 1.71 & 0.655 \\
\hline
\end{tabular}

*ANOVA test was used to compare all groups, and multiple range tests to identify the explanation of the detected differences.

Total counts: GAgP, versus LAgP and ChP.

A. actinomycetemcomitans: $\mathrm{ChP}$, versus $\mathrm{LApP}$ and $\mathrm{GAgP}$.

$P$. gingivalis : $\mathrm{GAgP}$ versus $\mathrm{ChP}$.

ChP $(\mathrm{p}=0.014)$. Finally, significant differences among groups for $T$. forsythia $(\mathrm{p}=0.028)$ corresponded to significant higher counts in generalized AgP, as compared to localized AgP ( $\mathrm{p}=0.027)$ and ChP $(\mathrm{p}=0.045)$ Table 3.

\section{Total anaerobic counts and counts of specific pathogens}

Total anaerobic counts were significantly different among groups $(\mathrm{p}=0.011)$, and the differences corresponded to higher levels in generalized AgP when compared to the other two groups. Also, significant differences among groups were detected for A. actinomycetemcomitans $(\mathrm{p}=0.019)$ and $P$. gingivalis $(\mathrm{p}=0.030)$, associated to lower counts in ChP as compared to the AgP groups, and to higher counts for generalized AgP as compared to ChP, respectively Table 4 .

\section{Discussion}

The results of the present cross-sectional study has shown distinct microbiological profiles for different types of periodontitis, namely localized and generalized AgP and ChP:. A. actinomycetemcomitans was significantly more frequent in generalized AgP than in ChP, and $P$. gingivalis was also more prevalent in generalized AgP than in both localized AgP and ChP. Other significant differences among conditions were detected for proportions of anaerobic microflora for A. actinomycetemcomitans, $P$. gingivalis and $T$. forsythia, and for total anaerobic counts and counts of A. actinomycetemcomitans and $P$. gingivalis.

Conversely, for other pathogens, similar results were found, such as for P. intermedia, Capnocytophaga spp., F. nucleatum, $P$. micra or $C$. rectus. These results may support previous data showing that, when considered as a whole, the subgingival microbiota may not differ significantly between AgP and ChP [21-26]. And, as showed in earlier worldwide studies on periodontal microbiota, this study confirm the presence and interspecies relationships of periodontopatic bacteria [11,27-29]. Ximenez-Fyvie et al. [26] employed the checkerboard DNA-DNA hybridization technique to describe the subgingival microbial composition of 77 Mexican subjects and found that the microbial differences between generalized AgP and generalized ChP subjects were only discrete and none of the 40 bacterial species tested seemed to specifically differentiate the subgingival microbial profile of either periodontitis groups. Takeuchi et al. [25] used polymerase chain reaction (PCR) to determine the prevalence and culture to study the proportion of seven subgingival species in samples from 93 Japanese subjects with AgP, ChP or healthy conditions. A significantly higher percentage of generalized AgP and generalized ChP were carriers of $C$.rectus, $P$. gingivalis, $T$. forsythia and Treponema denticola than periodontally healthy subjects. And the proportions of $A$. actinomycetemcomitans, $P$. gingivalis and $T$. forsythia were similar in all periodontitis groups. Heller et al. [30] evaluated the presence of 40 bacteria by the means of checkerboard DNA-DNA hybridization technique, on Brazilian population (75 individuals with AgP and 185 with $\mathrm{ChP}$ ). They found that only few species differed between AgP and ChP, P. gingivalis and T. denticola were related to $\mathrm{ChP}$, while Eubacterium nodatum was associated with AgP. The same authors reported that A. actinomycetemcomitans was very frequent in ChP and AgP and significant differences of $A$. actinomycetemcomitans between the two forms of disease are related to specific 
clone type or serotypes and not only the presence or levels of this pathogen. Mombelli et al. [23] evaluated whether the presence or absence of A. actinomycetemcomitans, P.gingivalis, P.intermedia, T.forsythia, and C. rectus could distinguish between ChP and GAgP. They concluded that these bacteria presented a limited interest in discriminatory ability to identify subjects with GAgP or ChP. However, a diagnosis of GAgP was more likely in subjects positive for Aa than subjects negative for this bacterieum. Moreover, the highly leukotoxic strain was uniquely associated with AgP. Mahalakshmi et al. [31] reported to that in addition to A. actinomycetemcomitans; the prevalence of P.gingivalis and T. forsythia was also high in periodontitis and while A. actinomycetemcomitans showed a positive association with AgP while T.denticola was associated with ChP.

In the present study, statistically significant differences regarding the frequency of detection were reported: e.g. A. actinomycetemcomitans was more frequently isolated in $\mathrm{AgP}$ than in $\mathrm{ChP}$ (60.0\% versus 25.0\%; $\mathrm{p}=0.080)$, supporting previous data showing that this bacterial species is highly associated with AgP in Morocco, either when using culture or PCR as a detection method [32,33]. In addition, despite the importance of $A$. actinomycetemcomitans in periodontitis, in the present report it was a frequent finding the co-occurrence of two or more species of the studied bacteria within the same patient. Ashimoto et al. [34] reported that there is a symbiotic relationship between micro-organisms in periodontal pockets. Indeed, a pathogen may colonize subgingival sites already occupied by other bacteria. Or some bacteria may occur together in periodontal lesions because they both produce destructive disease without interacting with each other.

P. gingivalis is highly prevalent among subjects with ChP [35-38]. In AgP, its frequency varies between 62\% and $100 \%$ in different populations $[25,39,40]$. In the present study, $P$. gingivalis was isolated in $82.0 \%$ and $60.0 \%$ of $\mathrm{AgP}$ and $\mathrm{ChP}$, respectively, and the differences were statistically significant. These results suggest that P. gingivalis may be also an important pathogen in AgP patients in Morocco. The presented frequencies are similar to the frequencies reported in Colombia $(74.6 \%$ and $68.2 \%$, respectively) [39] or Chile ( $88.8 \%$ and $76.4 \%$, respectively) [41].

In the present research, the frequency of $T$. forsythia isolation was slightly higher in AgP compared to $\mathrm{ChP}$. Botero et al. [42] reported a frequency of $50 \%$ in both forms of periodontitis in Colombia. Many studies suggested that $T$. forsythia is associated with progressive periodontitis [43-45] and "refractory" periodontitis [46,47]. More recently, Tomita et al. [48] studied the prevalence and levels of Aa, Pg and T. forsythia in subgingival plaque samples of a group of 40
Japanese patients with aggressive and chronic periodontitis (20 AgP and $20 \mathrm{ChP}$ ). The authors reported that no distinct pattern of the subgingival bacteria profile was discerned between the two entities, except for $\mathrm{T}$. forsythia which was significantly higher in $\mathrm{ChP}$ subjects than in $\mathrm{AgP}$ subjects. They added also that bacterial account for Pg and $\mathrm{T}$. forsythia were positively correlated with pockets depth and clinical attachment loss which corroborate the role of those bacteria belonging to the red complex in pathogenesis of periodontitis.

Based on the clinical examination (PPD, CAL) and radiographic patterns of periodontal destruction, AgP patients were subdivided into localized or generalized. The most frequent pathogens in both conditions were $P$. gingivalis (61.5\%), P. intermedia (84.6\%) and F. nucleatum (76.9\%), for localized AgP, and. P. gingivalis (89.2\%), P. intermedia (86.5\%), T. forsythia (64.9\%), and F. nucleatum (82.4\%), for generalized AgP. Lee et al. [22] used PCR to determine the prevalence of seven putative periodontal pathogens in 39 Korean AgP patients and reported that all the studied bacteria, A. actinomycetemcomitans (75\%), P. gingivalis (96.8\%), P. intermedia (78.8\%), T. forsythia (94.2\%), Fusobacterium spp. (99.4\%), Treponema spp. (96.8\%) and Parvimonas micra (85.9\%), were frequently associated with $\mathrm{AgP}$ in this population. In particular $P$. intermedia was significantly associated with generalized AgP. In Japan, subgingival samples were collected from 50 patients with AgP (10 localized, 40 generalized) and 35 samples from generalized ChP. T. forsythia and P. gingivalis were detected more frequently at sites where the attachment loss was severe (CAL $\geq 6 \mathrm{~mm}$ ), in comparison with those with moderate attachment loss $(\mathrm{CAL}<6 \mathrm{~mm})$ in patients with localized AgP. This trend was also observed for P. gingivalis, among patients with generalized AgP. However, the positive correlation between the presence of C. rectus/ $T$. denticola and the severity of the clinical attachment loss was not found in any of the three groups of periodontitis [25]. Kowalski et al. [49] reported that high frequency detection of $A$. actinomycetemcomitans and C. rectus in generalized $\mathrm{Ag}$ periodontitis. In our study C. rectus showed low occurrence either in aggressive periodontitis and chronic periodontitis it titers were low to in the two entities.

In our study, when studying the counts and proportions of cultivated bacteria, $P$. gingivalis and T. forsythia showed a stronger association to generalized AgP in comparison with either localized AgP or ChP. Thus, these results may suggest that $P$. gingivalis could play a major role in the pathogenesis of generalized $\mathrm{AgP}$ in this population. Conversely, no significant differences in the frequency of detection, counts or proportions were detected in the present study, between localized and generalized AgP for A. actinomycetemcomitans. These 
results are in contrast with previous data in a Moroccan population, using PCR, which showed that the presence of $A$. actinomycetemcomitans was significantly associated with localized Ag P compared to generalized AgP [32].

The previously mentioned discrepancy could be explained in part by the fact that PCR is more sensitive for bacterial detection, with lower detection thresholds (and localized AgP may harbor lower amounts of the target bacteria, as shown in Table 4). But also, by the fact that in the present study, the sampling strategy included a pooled subgingival sample of the four deepest pockets (one per quadrant) and, therefore, the occurrence of pathogens may have been underestimated. Other explanation could be the small sample size for localized comparing to generalized AgP. It should be also highlighted that culture cannot distinguish between high and low virulent strains of $A$. actinomycetemcomitans. Culture investigations have shown that the level of subgingival cultivated microbiota $A$. actinomycetemcomitans is lower than those of $P$. gingivalis in adult patients with periodontitis [50]. The difference between the levels of $A$. actinomycetemcomitans and $P$. gingivalis was also demonstrated by Rams et al. [29] who examined subgingival samples of 1,800 patients with periodontitis. The average proportion of $A$. actinomycetemcomitans in the microbiota was $4 \%$, while that of $P$. gingivalis was $23 \%$. Compared to other periodontal bacteria, such as $P$. intermedia/nigrescens, $C$. rectus or $P$. micra, the proportion of $P$. gingivalis was also higher [29].

Depending on criteria that a bacterium of total sub gingival cultivated flora above a certain minimal threshold to be associated with periodontitis, it has been suggested that this threshold is $0.1 \%$ for $P$. gingivalis [51], $0.01 \%$ for A. actinomycetemcomitans [36,51], 2.5\% for P. intermedia [43,51], 5\% for F. nucleatum and Capnocytophaga spp. [43,52], $1 \%$ for E. corrodens [43,52], and 2\% for $C$. rectus $[43,53]$.

Differences detected in the present study may not represent true differences in the population. The differences in percentages of detection of periodontal pathogens found worldwide between studies may be due to geographical differences, socio-economic status as well as to the genetic factor of the host. It is to note also that a strict comparison is difficult because of the detection method and laboratory standards may differ between team researchers, clinical criteria used in studies may be different to, mild or severe, localized or generalized periodontal breakdown. However, as mentioned by Lourenco et al. [54], a microbial consortium combining A.actinomycetemcomitans and other potential pathogens may be helpful to discriminate between AgP and CP. Further studies on large samples are needed. Microbiological aspect of periodontitis and especially aggressive periodontitis is peace of the complex multifactorial etiology that should be taken in consideration to help in better mentoring and treatment of this entity.

\section{Conclusions}

This study confirms the association of A. actinomycetemcomitans with localized and generalized AgP in Morocco, while $P$. gingivalis was highly associated with generalized AgP. Differences in frequency of detection, counts and proportions of A actinomycetemcomitans, $P$. gingivalis and T. forsythia suggests the presence of distinct microbiological profiles for localized AgP, generalized $\mathrm{AgP}$ and $\mathrm{ChP}$ patients. More studies are necessary to understand the role of these bacterial species in aggressive periodontitis pathogenesis.

\section{Competing interests}

The authors declare that they have no competing interests

\section{Authors' contributions}

$\mathrm{HC}$ carried out acquisition of data and draft the manuscript. MM carried out the acquisition of data and culture. $\mathrm{DH}$ participated in the design of the study, performed the statistical analysis and revised critically the manuscript MS participated in the design of the study and its coordination. OKE conceived of the study, participated to its coordination and collecting data, and revised critically the manuscript. All authors read and approved the final manuscript.

\section{Acknowledgments}

This study was supported by the Mohammed V Souissi University, Rabat Morocco (Grant 002/FMD/2011) and Faculty of Dentistry, University Complutense, Madrid, Spain. The authors thank Itziar González and Ana O'Connor for their valuable assistance at the Laboratory of the Faculty of Dentistry, University Complutense.

\section{Author details}

${ }^{1}$ EREB (Research Group of Oral Ecosystem), Faculty of Medicine Dentistry, Mohammed V University, Rabat, Morocco. ${ }^{2}$ ETEP (Etiology and Therapy of Periodontal Diseases) Research Group, Faculty of Dentistry, University Complutense, Madrid, Spain.

Received: 22 July 2014 Accepted: 9 February 2015

Published online: 24 February 2015

\section{References}

1. Philstrom BL, Michalowicz BS, Johnson NW. Periodontal diseases. Lancet. 2005;366:1809-20.

2. Sanz M, van Winkelhoff AJ. Periodontal infections: understanding the complexity. Consensus of the Seventh European Workshop on Periodontology. J Clin Periodontol. 2011;38 Suppl 11:3-6.

3. Socransky SS, Haffajee AD. Periodontal microbial ecology. Periodontol 2000. 2005:38:135-87.

4. Faveri M, Figueiredo LS, Duarte PM, Mestnik MJ, Mayer MP, Feres M. Microbiological profile of untreated subjects with localized aggressive periodontitis. J Clin Periodontol. 2009;36:739-49.

5. Cortelli JR, Cortelli SC, Jordan S, Haraszthy VI, Zambon JJ. Prevalence of periodontal pathogens in Brazilians with aggressive or chronic periodontitis. J Clin Periodontol. 2005;32:860-6.

6. Feng Z, Weinberg A. Role of bacteria in health and disease of periodontal tissues. Periodontol 2000. 2006:40:50-76.

7. Curtis MA, Slaney JM, Aduse-Opoku J. Critical pathways in microbial virulence. J Clin Periodontol. 2005;32 Suppl 6:28-38.

8. Schenkein HA. Host responses in maintaining periodontal health and determining periodontal disease. Periodontol 2000. 2006;40:77-93.

9. Socransky SS. Relationship of bacteria to the etiology of periodontal disease. J Dent Res. 1970;49:203-22. 
10. Fives-Taylor PM, Meyer DH, Mintz KP, Brissette C. Virulence factors of Actinobacillus actinomycetemcomitans. Periodontol 2000. 1999;20:136-67.

11. Mullally BH, Dace B, Shelburne CE, Wolff F, Coulter WA. Prevalence of periodontal pathogens in localized and generalized forms of early-onset periodontitis. J Periodontal Res. 2000;35:232-41.

12. Nishihara T, Koseki T. Microbial etiology of periodontitis. Periodontol 2000. 2004;36:14-26.

13. Haubek D, Ennibi O, Poulsen K, Poulsen S, Benzarti N, Kilian M. Early onset periodontitis in Morocco is associated with the highly leucotoxic clone of Actinobacillus actinomycetemcomitans. J Dental Res. 2001;80:1580-3.

14. Haubek D, Ennibi O, Poulsen $K$, Væth M, Poulsen S, Benzarti N, et al. Risk of aggressive periodontitis in adolescent carriers of the JP2 clone of Aggregatibacter (Actinobacillus) actinomycetemcomitans in Morocco: a prospective longitudinal cohort study. Lancet. 2008;371:237-42.

15. Chahboun $\mathrm{H}$, Filali Maltouf A, Ennibi O. Aggregatibacter actinomycetemcomitans and Porphyromonas gingivalis in aggressive periodontitis in Morocco- preliminary study. Odontstomatol Trop. 2013;36:5-10.

16. Armitage $\mathrm{G}$. Development of a classification system for periodontal diseases and conditions. Ann periodontol. 1999:4:1-6.

17. Syed SA, Loeshe WJ. Survival of human dental plaque flora in various transport media. Appl Microbiol. 1972;24:638-44.

18. Dahlén $\mathrm{G}$, Renvert $\mathrm{S}$, Wikstrom M, Egelberg J. Reproducibility of microbiological samples from periodontal pockets. J Clin Periodontol. 1990;17:73-7.

19. Alsina M, Olle E, Frias J. Improved, low cost selective culture medium for Actinobacillus actinomycetemcomitans. J Clin Microbiol. 2001;39:509-13.

20. Slots J. Bacterial specificity in adult periodontitis. A summary of recent work. J Clin Periodontol. 1986;13:912-7.

21. Mahalakshmi K, Krishnan P, Chandrasekaran SC, Panishankar KH, Subashini N. Prevalence of periodontopathic bacteria in the south subgingival plaque of a south indian population with periodontitis. J Clin Diag Res. 2012;4 suppl 2:747-52

22. Lee J, Choi B, Yoo Y, Choi S, Cho K, Chai J, et al. Distribution of periodontal pathogens in Korean aggressive periodontitis. J Periodontol. 2003;74:1329-35.

23. Mombelli A, Casagni F, Madianos PN. Can presence or absence of periodontal pathogens distinguish between subjects with chronic and aggressive periodontitis? A systematic review. J Clin Periodontol. 2002;29 Suppl 3:10-21.

24. Picolos DK, Lerche-Sehm J, Abron A, Fine JB, Papapanou PN. Infection patterns in chronic and aggressive periodontitis. J Clin Periodontol. 2005:32:1055-61.

25. Takeuchi Y, Umeda M, Ishizuka M, Huang Y, Ishikawa I. Prevalence of periodontopathic bacteria in aggressive periodontitis patients in a Japanese population. J Periodontol. 2003;74:1460-9

26. Ximenez-Fyvie LA, Almaguer-Flores A, Jacobo-Soto V, Lara-Cordoba M, Moreno-Borjas JY, Alcantara-Maruri E. Subgingival microbiota of periodontally untreated Mexican subjects with generalized aggressive periodontitis. J Clin Periodontol. 2006;33:869-77.

27. Ali RW, Velcescu C, Jivanescu MC, Lofthus B, Skaug N. Prevalence of 6 putative periodontal pathogens in subgingival plaque samples from Romanian adult periodontitis patients. J Clin Periodontol. 1996:23:133-9.

28. Doğan B, Antinheimo J, Çetiner D, Bodur A, Emingil G, Buduneli E, et al. Subgingival microflora in Turkish patients with periodontitis. J Periodontol. 2003;74:803-14.

29. Rams TE, Flynn MJ, Slots J. Subgingival microbial associations in severe human periodontitis. Clin Infect Dis. 1977;25 Suppl 2:S224-6.

30. Heller DB, Silva-Boghossian CM, do Souto RM, Colombo APV. Subgingival microbial profiles of generalized aggressive and chronic periodontal diseases. Arch Oral Biol. 2012;57:973-80.

31. Mahalakshmi K, Krishnan P, Chandrasekaran SC, Panishankar KH, Subashini N. Prevalence of periodontopathic bacteria in the subgingival plaque of a South Indian population with periodontitis. J Clin Diagn Res. 2012;6:747-52.

32. Ennibi O, Benrachadi L, Bouziane A, Haubek D, Poulsen K. The highly leukotoxic JP2 clone of Aggregatibacter actinomycetemcomitans in localized and generalized forms of aggressive periodontitis. Acta Odontol Scand. 2012:70:318-22

33. Haubek D, Ennibi O, Abdellaoui L, Benzarti N, Poulsen S. Attachment loss in Moroccan early-onset periodontitis patients. J Clin Periodontol. 2002;29:657-60

34. Ashimoto A, Chen C, Bakker I, Slots J. Polymerase chain reaction detection of 8 putative periodontal pathogens in subgingival plaque of gingivitis and advanced periodontitis lesions. Oral Microbiol Immunol. 1996;11:266-73.

35. Ali RW, Bakken V, Nilsen R, Skaug N. Comparative detection frequency of 6 putative periodontal pathogens in Sudanese and Norwegian adult periodontitis patients. J Periodontol. 1994;65:1046-52.

36. Ali RW, Johannessen AC, Dahlén G, Socransky SS, Skaug N. Comparison of the subgingival microbiota of periodontally healthy and diseased adults in northern Cameroon. J Clin Periodontol. 1997;24:830-5.

37. Dahlén G, Manji F, Baelum V, Fejerskov O. Black-pigmented bacteroides species and Actinobacillus actinomycetemcomitans in subgingival plaque of adult Kenyans. J Clin Periodontol. 1989;16:305-10.

38. Hamlet SM, Cullinan MP, Westerman B, Lindman M, Bird PS, Palmer J, et al Distribution of Actinobacillus actinomycetemcomitans, Porphyromonas gingivalis and Prevotella intermedia in an Australian population. J Clin Periodontol. 2001;28:1163-71.

39. Lafaurie Gl, Contreras A, Baron A, Botero J, Mayoga-Fayad I, Jaramillo A, et al. Demographic, clinical, and microbial aspects of chronic and aggressive periodontitis in Colombia : A multicenter study. J Periodontol. 2007;78:629-39.

40. da Silva-Boghossian CM, do Souto RM, Luiz RR, Colombo APV. Association of red complex, A. actinomycetemcomitans and non-oral bacteria with periodontal diseases. Arch Oral Bio. 2011;56:899-906.

41. Gajardo M, Silva N, Gomez L, Leon R, Parra B, Contreras A, et al. Prevalence of periodontopathic bacteria in aggressive periodontitis patients in a Chilean population. J Periodontol. 2005;76:289-94.

42. Botero JE, Contreras A, Lafaurie G, Jaramillo A, Betancourt M, Arce RM. Occurrence of periodontopathic and superinfecting bacteria in chronic and aggressive periodontitis subjects in a Colombian population. J Periodontol. 2007;78:696-704

43. Dzink JL, Socransky SS, Haffajee AD. The predominant cultivable microbiota of active and inactive lesions of destructive periodontal diseases. J Clin Periodontol. 1988;15:316-23.

44. Haffajee AD, Socransky SS, Dzink JL, Taubman MA, Ebersole JL, Smith DJ. Clinical, microbiological and immunological features of subjects with destructive periodontal diseases. J Clin Periodontol. 1988;15:240-6.

45. Van Winkelhoff AJ, Loos BG, van der Reijden WA, van der Velden U. Porphyromonas gingivalis, Bacteroides forsythus and other putative periodontal pathogens in subjects with and without periodontal destruction. J Clin Periodontol. 2002;29:1023-8.

46. Haffajee AD, Socransky SS, Dzink JL, Taubman MA, Ebersole JL. Clinical, microbiological and immunological features of subjects with refractory periodontal diseases. J Clin Periodontol. 1988;15:390-8.

47. Winkel EG, Van Winkelhoff AJ, Timmerman MF, Vangsted T, Van der Velden $U$. Effects of metronidazole in patients with "refractory" periodontitis associated with Bacteroides forsythus. J Clin Periodontol. 1997;24:573-9.

48. Tomita S, Komiya-Ito A, Imamura K, Kita D, Ota K, Takayama S, et al. Prevalence of Aggregatibacter actinomycetemcomitans, Porphyromonas gingivalis and Tannerella forsythia in Japanese patients with generalized chronic and aggressive periodontitis. Microb Pathog. 2013;61-62:11-5.

49. Kowalski J, Górska R. Clinical and microbiological evaluation of biofilmgingival interface classification in patients with generalized forms of periodontitis. Pol J Microbiol. 2014;63:175-81.

50. Van der Weijden GA, Timmerman MF, Reijese E, Wolffe GN, van Winkelhoff, van der Velden $U$. The prevalence of $A$. actinomycetemcomitans, $P$. gingivalis and $P$. intermedia in selected subjects with periodontitis. J Clin Periodontol. 1994; 21:583-8.

51. Bragd L, Dahlén G, Wikstrom M, Slots J. The capability of Actinobacillus actinomycetemcomitans, Bacteroides gingivalis, and Bacteroides intermedius to indicate progressive periodontitis; a retrospective study. J Clin Periodontol. 1987:14:95-9.

52. Dzink JL, Tanner AC, Haffajee AD, Socransky SS. Gram negative species associated with active destructive periodontal lesions. J Clin Periodontol. 1985;12:648-59.

53. Tanner AC, Dzink JL, Ebersole JL, Socransky SS. Wolinella recta, Campylobacter concisus, Bacteroides gracilis, and Eikenella corrodens from periodontal lesions. J Periodontal Res. 1987;22:327-30.

54. Lourenço TG, Heller D, Silva-Boghossian CM, Cotton SL, Paster BJ, Colombo AP. Microbial signature profiles of periodontally healthy and diseased patients. J Clin Periodontol. 2014:41:1027-36. 